\title{
Use of Cotton Apparel Waste as an Energy Source for Biomass Boilers: A Feasibility Study
}

\author{
Wadumesthri Chethiya Prasanga ${ }^{1}$, Amalka Nawarathna ${ }^{2}$, Pavithra Rathnasiri ${ }^{3 *}$ \\ ${ }^{1}$ Department of Building Economics, University of Moratuwa, Colombo 00100, Sri Lanka \\ ${ }^{2}$ Department of Architecture and Built Environment, Northumbria University, Newcastle upon Tyne, NE1, United Kingdom \\ ${ }^{3}$ Division of Building Science and Technology, City University of Hong Kong, Kowloon 999077, Hong Kong SAR
}

Corresponding Author Email: stprathnasiri@gmail.com

https://doi.org/10.18280/ijdne.160106

Received: 21 September 2020

Accepted: 11 January 2021

\section{Keywords:}

apparel manufacturing industry, apparel waste, biomass boilers, feasibility

\begin{abstract}
The steady growth of the Sri Lankan apparel manufacturing sector over the last three decades has resulted in generating large amount of solid apparel waste. Currently, it is a massive environmental and financial burden of the sector. As a solution, few apparel manufacturers have initiated using apparel waste, specifically the cotton apparel waste for biomass boilers. The apparel sector as one of the major thermal energy consumers, they consider it as a possible solution not only for the apparel waste disposal issue, but also for the challenge of getting continuous supply of firewood for the boilers. However, the promotion of such a solution throughout the apparel industry is impractical without a feasibility study in terms of social, environmental, financial, legal and technical aspects over its mechanism. Therefore, this research focused to identify the feasibility of using cotton apparel waste for biomass boilers as an energy source. Towards this aim, a qualitative research approach was followed involving the case study strategy. Basically, two cases were selected and analysed the feasibility of using cotton waste for boilers under pre-determined feasibility criteria in detail. Data collection for the case study was done through a document survey and expert interviews. Findings revealed the entire feasibility of environmental, financial, legal and technical aspects and in overall it can be concluded that the use of cotton apparel waste for biomass boilers as an energy source is feasible. Accordingly, this study provides insights into making decisions on managing both waste disposal and heat energy requirement issues of the apparel factories.
\end{abstract}

\section{INTRODUCTION}

Statistically, global textile production is approximately 140.84 million and apparel industry is utilizing 19,000 to 38,000 tons of fabrics annually, while creating a huge waste by more than $20 \%$ from used fabric [1]. To manage the massive generation of apparel fabric waste, numerous waste management practices are being practiced nowadays [2]. The most common practices currently used are incineration and landfilling respectively at a rate of $13 \%$ and $74 \%[3,4]$. In Europe, the estimated fabric waste generation per annum is 5.8 million tons. Even though, recycling, incineration and landfilling are used to control the production of fabric waste, the adversative impacts for the environment through those practices are considerably high due to the increased amount of greenhouse gasses including carbon dioxide and methane [5]. Hence, Punchihewa et al. [6], mentioned that reusing of fabric waste is significant than releasing them to the environment. On the other hand, Bodur et al. [7] has asserted that reusing of waste to generate energy is more beneficial against all other disposal techniques. However, reusing is not widely practicing due to its practical issues [6]. Therefore, from industrial point of view, with the high demand for producing thermal energy, this has paved the way in investigating potential strategies for the use of fabric waste to produce thermal energy [3]. Nunes et al. [8] have further established that, there is a huge potential in producing thermal energy using fabric waste.

In apparel manufacturing sector, thermal energy is mainly used to produce saturated or superheated steam by the use of boilers [9]. As mentioned by Choi et al. [10], thermal energy is the main energy type used in apparel industry and therefore, the fundamental requirement of apparel industry is fulfilling the thermal energy requirement. Simultaneously, managing excessive fabric waste has been a considerable issue with the continuous productions of garments. When focusing on countries like Sri Lanka, where apparel manufacturing takes a greatest share to the overall economic development, there is a tremendous importance in introducing an innovative method to produce thermal energy by using disposable fabric waste [11]. At present, biomass boilers which operates with firewood, are widely used in apparel manufacturing factories in Sri Lanka and Gliricidia and rubberwood can be considered as major types of firewood used for biomass boilers. However, as another significant issue, currently they face the difficulty of getting the continues supply of firewood for biomass boilers. Therefore, few apparel manufacturing companies in Sri Lanka are currently practicing the use of cotton waste to biomass boilers as an energy source. However, according to Ryu et al. [12], even though apparel waste comprises high energy content, a detailed survey should be carried out to examine the environmental, financial, legal, technical and social feasibility for the use of cotton apparel waste as an alternative fuel type for biomass boilers. Similarly, Nunes et al. [8] have also established that, there is a need of conducting a rigorous study to evaluate the possibility and practicability of the use of cotton waste as an energy source for biomass boilers. Al Afif 
et al. [13] have also mentioned that, even it says there is a potential to produce bioenergy by using cotton stalks, more studies are needed to prove the effectiveness of cotton waste utilization. However, when analysing the existing studies focusing on this regard, it can be mentioned that the research efforts available are considerably less in both local and global contexts [8]. Evidently, there are no studies available in recent years identifying the actual potential of using cotton waste to produce thermal energy for boilers, even though very few past studies are available at discussion level. Thus, this study has focused to assess the feasibility of using cotton apparel waste as a potential energy source for biomass boilers.

\section{LITERATURE REVIEW}

\subsection{Apparel manufacturing in Sri Lanka and its waste management}

Apparel industry is the most significant contributor to the Sri Lankan economy as it has made a steady growth over the past few decades. Sri Lankan apparel industry has been evolved from traditional model of production to sophisticated and multifaceted solutions fulfilling the emerging global needs [14]. Creating reputed innovative developments in island's entire apparel manufacturing, Sri Lanka's apparel industry has transformed the country's global apparel market into a regional apparel hub. Currently, the apparel sector occupies 15\% of workforce and Sri Lanka has been one of the highest apparel exporters in the region [11]. The main export markets of Sri Lankan apparel sector include USA, UK, Italy, Germany, Canada, France, Netherlands, Australia, China, Japan and Korea as per 2019. The continuous increase in Sri Lankan apparel sector from 2012 to 2018 and global market share [14] are shown in Figure 1.
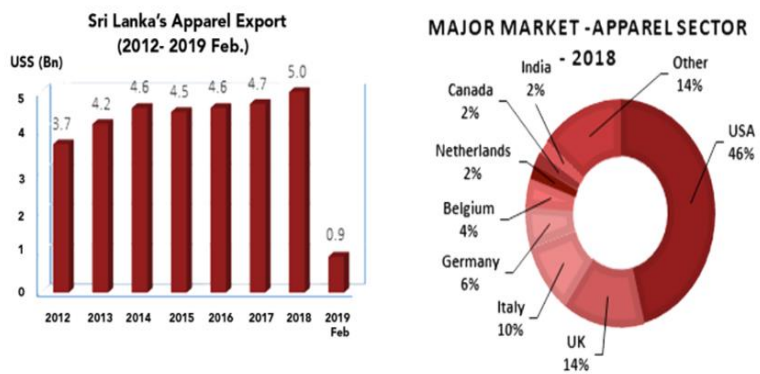

Figure 1. Growth of apparel demand and global market share Source: [14]

With the rapid increase in the development of apparel manufacturing, it has become important to consider the waste management especially due to the generation of apparel waste. In this perspective, Sri Lankan apparel industry is currently practicing the 3R (Reuse, Recycle, Reduce) waste management concept according to the waste management hierarchy [14]. Further, open dumping and incineration are also being practiced [15]. However, due to massive productions of garments, current methods have been unable to manage the generation of substantial apparel waste and apparel industry is currently being suffered with the issue of managing apparel waste as it contributes to adverse environmental impacts as well [6]. It has been a major burden to the apparel sector in Sri Lanka as they have been bounded and regulated by the government waste management policies and regulations as well.

\subsection{Cotton apparel waste as an alternative energy source for biomass boilers}

\subsubsection{Biomass boiler operations in apparel industry}

The primary function of the boiler can be described as transferring the heat produced by incineration to water used in the heating system [16]. Boilers are used mainly in the apparel industry to fulfil the requirements of heating water for washing machines, generate steam for tumblers to dry garments, generate steam for steam heated fusing machines, air compression systems and irons [17]. Boilers used in large scale apparel manufacturing processes, can be classified based on several criteria including the type of fuel in use, type of tube and methods of combustion. Based on the type of fuel used, boilers are categorized as furnace boilers which operates with furnace oil and biomass boilers which use firewood [15]. When it comes to biomass boilers, operation of biomass boilers is quite different since it is using the method of biomass combustion process consisting consecutive heterogeneous and homogeneous chemical reactions carried out in different steps which include drying, devolatilization, gasification, char combustion and gas-phase oxidation [18].

\subsubsection{Use of firewood for biomass boilers}

The major fuel type used in almost all the countries for biomass boilers is firewood. However, there are significant challenges which have been mentioned in prevailing literature, for the use of firewood for biomass boilers [19]. As stated by Halimi et al. [20], the moisture content exists in the firewood make a considerable impact over the final output, since more heat will be consumed for the moisture evaporation and thereby less efficiency in combustion of biomass. The composition of numerous particles and ash in firewood has also been mentioned as a significant issue of firewood which reduce the efficiency of boilers. Furthermore, calorific value of the firewood is also significant. Since the density of firewood is high, its tendency for burning and the calorific value becomes low, making inevitable issues in the boiler system [13].

Additionally, Nunes et al. [21] stated that, oxidation is not always complete and small amounts of carbon monoxide, hydrocarbons and other gases, such as nitrogen/sulphur oxides are released from firewood during the combustion. Some of these are harmful to health, some to the environment and atmosphere, which are commonly called as greenhouse gases. According to the Department of Environmental Affairs and Tourism in South Africa [22], particulate emissions from wood burning within South Africa is about 50\% elemental carbon and $50 \%$ condensed hydrocarbons. When considering the environmental unbalancing like global warming, biomass is considered to be carbon neutral since it says that the carbon dioxide released in the combustion phase equals the carbon dioxide absorbed during the growth of a same amount of wood in forest [23]. However, Pierobon et al. [24] mentioned that, according to the life cycle analysis of firewood there is a possibility of occurring negative impacts to the environment over firewood. In other hand, the supply chain of firewood, when there is a considerable distance from the site of acquisition of raw firewood to the utilization site plays an important role in the overall carbon footprint [25]. A case study conducted in Italy, related to life cycle environmental 
impact of firewood production has elaborated that, off-road long supply chain transport results $58.44 \%$ of global warming potential (GWP) and on-road short transport results $6.57 \%$ of GWP, expressed in terms of carbon dioxide equivalents [13].

Furthermore, most of profit in firewood market is retained by transporters despite their small share of engagement in the overall value chain [13]. Farmers and wood harvesters, who represent the largest group in the value chain, receive a very small share from overall profits. This is one of the considerable social impact arise by the use of firewood. The profits gained are not shared equally between the parties who are involved in the supply chain of firewood. Hence, though demand for firewood is very high in the local apparel sector, there are practical issues in the use of firewood from environmental, social, economic aspects. Mainly, there is an adverse impact for the environment due to the emission of $\mathrm{GHG}$ from combustion. Considering the drawbacks arise from firewood as mentioned above, it is ideal to go for an alternative which minimizes the overall impact of combustion and operation of biomass boilers [13, 26]. Saidur et al. [27] have also stated that, depositions and collections of layers of materials specially ash over the surfaces of boilers is a significant issue. In addition to that, the corrosion, high carbon dioxide emissions, deterioration of combustion behavior with higher combustion temperatures, high nitrogen oxides and carbon monoxide emissions have been mentioned as prevailing issues of biomass boilers operated with firewood [21]. Focusing these issues, Hamawand et al. [28] expressed that, there is a critical need for shifting to an alternative energy source for biomass boilers and specially in apparel sector, there is a possibility of using cotton waste as the best alternative.

\subsubsection{Cotton apparel waste as an alternative for firewood}

Cotton is one of the main raw materials of all fibre types, which takes a large share in apparel industry [29]. The annual production of cotton is more than 23 million tons per year and uses $1 / 3$ of the global market for garment manufacturing [30]. Olowa, O.A. and Olowa, O.W. [31] mentioned that, cotton is a good alternative to be used as a fuel since it comprises the required properties as a type of fuel. Similarly, Nunes et al. [8] mentioned that cotton has a high degree of converting into useable form of energy. Nunes et al. [21] mentioned that cotton waste in textile industry has a huge potential to be used as an alternative to natural gas, wood pallets and wood chips. Al Afif et al. [13] have further explained that, the use of cotton waste as a type of fuel may result with number of advantages as it could eliminates the cost of landfills, transportations, operation costs and deposition rates, increases the latter's life by avoiding low-density high-volume materials to landfills, and reduces the costs of producing heat using other type of fuels. Avelar et al. [29] have highlighted in their study, the potential of using textile waste mixing with sludge from wastewater treatment plants as an alternative for the traditional fuel types used. Nunes et al. [8] have further investigated the characterization of cotton waste through laboratory tests and revealed that cotton waste has very interesting potential and close properties as wood and thus to be used as an alternative fuel to wood. Moreover, authors have demonstrated an economic evaluation highlighting the cost effectiveness of using cotton waste compared to wood pallets and chips.

With regard to the Sri Lankan context, as biomass boilers are yet widely used in Sri Lankan apparel sector, which are fueled by firewood, it has been difficult to get a continuous supply of firewood to ensure its smooth operation while complying with the global apparel demand. With all concerns on managing excessive fabric waste and issues in fulfilling the demand of firewood for biomass boilers, currently there is a growing need for alternative forms of energy in Sri Lankan apparel sector. Thus, considering all the issues in local and global contexts, it is worth to consider the cotton waste as an alternative energy source.

\section{METHODOLOGY}

The selection of research approach basically depends on the purpose of study, type and availability of the information for the research. The qualitative approach can be used for the situations where data are expressed in words describing attitudes, opinions, feelings, ideas, values and believes which cannot be expressed in numbers. In this approach, the open ended and emerging data and opinions are expected. The aim of this research is to identify the feasibility of using cotton apparel waste for biomass boilers as an energy source in apparel manufacturing sector in Sri Lanka. To achieve this aim, it is important to get an in depth understanding about the positive and negative impacts of using cotton waste to biomass boilers from different perspectives. Thus, it is required to conduct an in-depth analysis of cases, where qualitative approach was deemed to be most suitable research approach for this study over the quantitative method.

Under qualitative research approach, case studies were conducted as the research strategy. The unit of analysis of this study is large-scale garment factories which utilize cotton waste as an energy source for biomass boilers and the case study boundary is the apparel manufacturing sector in Sri Lanka. Accordingly, two cases were selected as Case A and Case $\mathrm{B}$, leading to a comparative study. Case $\mathrm{A}$ is a garment factory which is located in Western province and one of the leading factories in large scale apparel sector in Sri Lanka. The boiler related services are carried out by the facility management department of the organization. Case B is another garment manufacturing factory, which is located in Southern province and a prominent factory in large scale apparel manufacturing in Sri Lanka. The particular factory provides various high-quality garments to foreign markets under one roof of management. Data collection of this study was done by semi-structured interviews and a document survey. Profile of the respondents is presented in Table 1 .

Besides, documents referred to the document survey conducted in this study is presented in Table 2.

Moreover, the data congregated through interviews were analyzed using content analysis method and the data collected through the document survey were analyzed through the ReCiPe Endpoint(H)/Europe ReCiPe analysis method. Further, the findings were demonstrated using charts and graphs for better understanding.

Table 1. Profile of respondents

\begin{tabular}{cccc}
\hline Case & Respondents & Profession & Experience \\
\hline Case A & R1 & $\begin{array}{c}\text { Facilities } \\
\text { Manager } \\
\text { Maintenance } \\
\text { Engineer }\end{array}$ & 8 Years \\
& R2 & Years \\
\hline Case B & R3 & $\begin{array}{c}\text { Facilities } \\
\text { Manager } \\
\text { Boiler } \\
\text { Engineer }\end{array}$ & 10 years \\
& R4 & years \\
\hline
\end{tabular}


Table 2. Materials used for the document survey

\begin{tabular}{ccc}
\hline Referred Document & $\begin{array}{c}\text { Case } \\
\text { A }\end{array}$ & $\begin{array}{c}\text { Case } \\
\text { B }\end{array}$ \\
\hline $\begin{array}{c}\text { Boiler maintenance document, manuals and } \\
\text { audit reports }\end{array}$ & $\checkmark$ & $\checkmark$ \\
\hline $\begin{array}{c}\text { Board of Investment (BOI) legal approved } \\
\text { documents }\end{array}$ & $\checkmark$ & $\checkmark$ \\
\hline Fabric testing reports & $\checkmark$ & $\checkmark$ \\
\hline $\begin{array}{c}\text { Central Environmental Authority (CEA) } \\
\text { approved documents }\end{array}$ & $\checkmark$ & $\checkmark$ \\
\hline BOI regulations document & $\checkmark$ & $\checkmark$ \\
\hline Firewood purchased records & $\checkmark$ & $\checkmark$ \\
\hline
\end{tabular}

\section{RESEARCH FINDINGS AND ANALYSIS - CASE STUDY}

\subsection{Need of using cotton waste as an energy source for boilers}

As the first section of this study, current apparel waste management practices were identified through semi-structured expert interviews from the selected two cases. The information was gathered from R1 and R2 from case A and R3 and R4 from case B. Mainly, the information about apparel waste generation and waste management practices and regulations were collected and discussed in order to identify the need of using cotton waste as an energy source for boilers.

As revealed by respondents, cotton waste, papers, plastics, cardboards and food waste are the primary contributors of waste generation in apparel manufacturing sector, and cotton waste is the main type of waste produced in factories. The average amount of cotton waste generated in case $\mathrm{A}$ is about 5 tons per day, while 2 tons of cotton waste are generated per day in case B. In terms of the volume, cotton waste has taken highest contribution to the total waste generation in both cases, where more attention needs to be given in managing this waste, especially in utilizing the generated waste and making waste as a resource to the organization. To ensure the proper waste management, both organizations strongly follow the waste management policies which include monitoring and recording of waste and disposal information, 3R strategy to reuse, recycle and recover the waste, environmentally sound waste disposal strategies and training and awareness programs for best management procedures. However, due to the massive generation of cotton waste, it has been a practical issue for both organizations to reduce and control the cotton waste, though other types of wastes can be properly managed.

The previous practice followed by case A, to reduce the cotton waste is, selling them to small scale manufacturers which have secondary use and sending the remaining small fabric parts to an outside company by paying them with an additional cost. As mentioned by respondents in case $\mathrm{B}$, the usual practice that they have followed in the past is, selling the cotton waste in a public auction and sending the remaining cotton waste to an outside company for incineration. However, respondents in both cases mentioned that it was time consuming, financially ineffective and in some seasons, it was not practical to reduce the cotton waste due to the high demand and production of garments in their factories. Considering these practical issues engaged with cotton waste, after a proper investigation, both organizations are currently used the cotton waste to the boilers to produce approximate thermal energy, while the rest is destroyed by incineration.
Accordingly, after collecting the aforementioned information, the basic need of using cotton waste as an energy source to the boilers was identified in this study.

\subsection{General information of the boilers used, sources of energy and management practices}

As the second section of this study, types of boilers, uses, energy sources and management practices of boilers that are currently used in selected cases were identified. Table 3 summarizes the gathered information of both case A and case B.

Table 3. Types of boilers, uses, energy sources and management practices

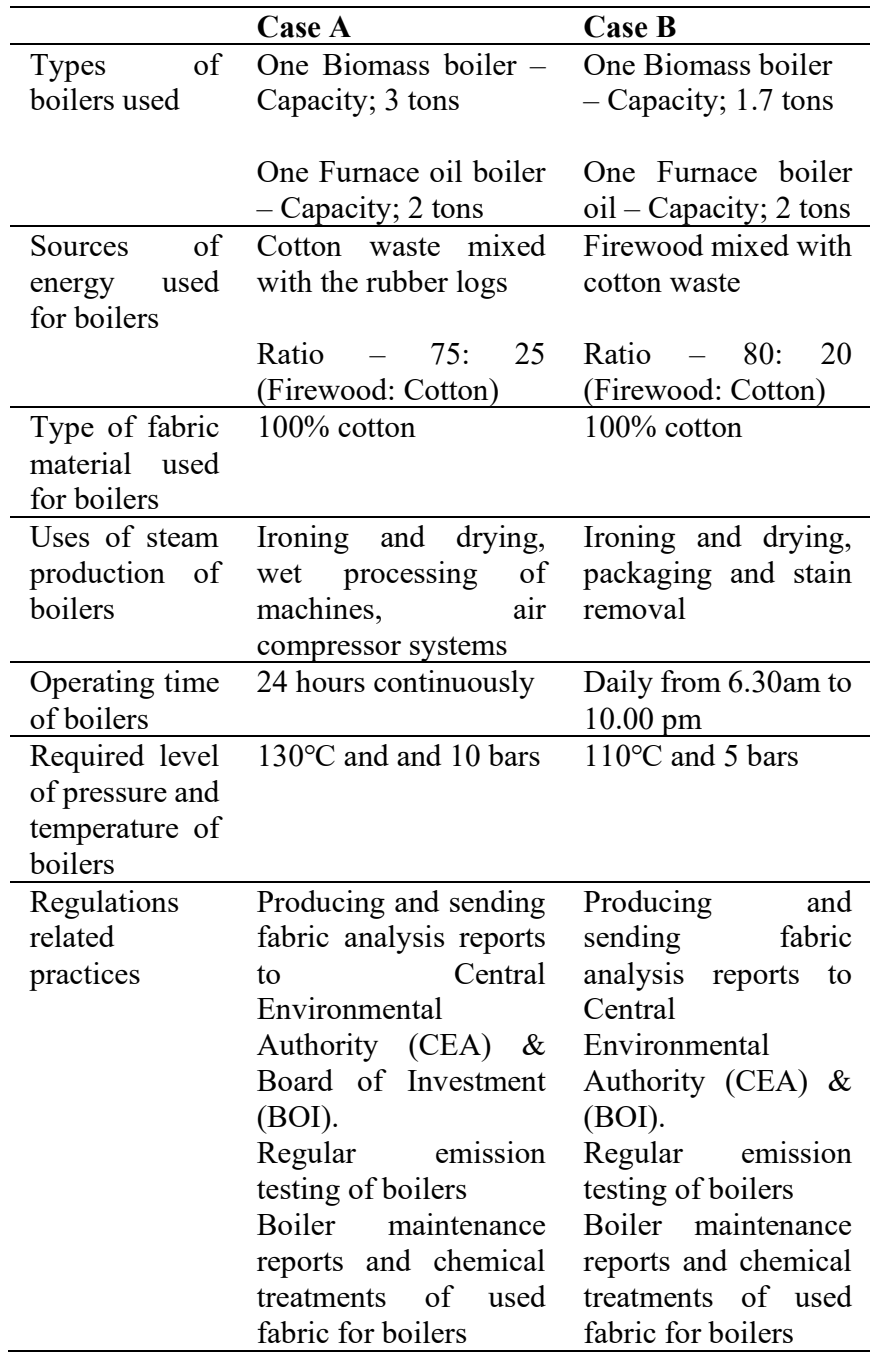

\subsection{Feasibility study for the use of cotton waste as an energy source for biomass boilers}

As the third section of this study, feasibility study was conducted under the predetermined criteria from literature. Basically, financial feasibility, technical feasibility, environmental feasibility, legal feasibility and social feasibility were determined $[12,13]$

\subsubsection{Financial feasibility}

Financial feasibility for the use of cotton waste for boilers was analyzed from the data collected from both cases. Financial feasibility is discussed under four aspects as financial savings from using cotton waste as fuel, cost savings 
from waste management, payback period for installed new controllers and unit price of steam generation. Financial feasibility was separately analyzed in case A and case B. Cost reports of purchased firewood were used to collect the financial data of both cases. Cost is shown in Sri Lankan Rupees (LKR).

Case A.

The current usage of cotton waste for the biomass boiler in case $\mathrm{A}$, is proportionately done by mixing with rubber logs as 3:1 ratio. According to the regulations and requirements governed by CEA and BOI in Sri Lanka, the firewood and rubber logs used for boilers should be purchased by government registered parties. In accordance to the cost reports of 2018 and 2019, the purchase costs of rubber logs are indicated in Table 4.

Table 4. Purchase costs of firewood

\begin{tabular}{ccccc}
\hline Year & Type of used energy source & Amount Purchased (kg) & Rate (LKR/kg) & $\begin{array}{c}\text { Total Annual Cost } \\
\text { (LKR) }\end{array}$ \\
\hline \multirow{2}{*}{ Nov 2017 - Oct 2018 } & Rubber firewood & 371,440 & 6.10 & $2,265,784$ \\
Nov 2018 - Oct 2019 & Rubber firewood & 133,655 & 5.50 & $735,102.5$ \\
& Total Financial Saving & 6.10 & $2,372,430.3$ \\
& & & $628,456.2$ \\
\hline
\end{tabular}

Before the use of cotton waste for the boilers (for the period Nov 2017 - Oct 2018), the total annual purchasing costs of firewood was LKR 3,000,886.5. However, with the start of using $25 \%$ cotton waste from November 2018 , the requirement of rubber firewood as fuel for the boiler decreased, resulting cost savings of LKR 628,456.2 for the subsequent one-year period November 2018 - October 2019. Similarly, in case B, total saving has been mentioned as LKR 450,036.3, as depicted in Table 5.

Case B.

Table 5. Purchase cost of firewood

\begin{tabular}{ccccc}
\hline Year & Type of used energy source & Amount Purchased (cubic yard) & Rate (LKR/cubic yard) & $\begin{array}{c}\text { Total Annual Cost } \\
\text { (LKR) }\end{array}$ \\
\hline Nov 2017- Oct 2018 & Rubber firewood & 875 & 1071.42 & $937,492.5$ \\
Nov 2018- Oct 2019 & Rubber firewood & 455 & 1071.42 & $487,496.1$ \\
& \multicolumn{2}{c}{ Total Financial Saving } & & $450,036.3$ \\
\hline
\end{tabular}

Transportation cost saving. In addition, the respondents from both the cases reported that, due to decrease of rubber firewood use, the number of trips to bring firewood to the factory was approximately halved. This resulted in a significant cost saving in terms of transport cost to case A.
However, this cost saving for case B was not that significant as the point of purchase of firewood was not that far from the factory.

The transport cost saving calculation is depicted in Table 6 .

Table 6. Transportation cost savings

\begin{tabular}{ccccccc}
\hline Case & $\begin{array}{c}\text { Round trip } \\
\text { distance } \mathbf{( k m )}\end{array}$ & $\begin{array}{c}\text { Average fuel efficiency of the } \\
\text { vehicles (km/l) }\end{array}$ & $\begin{array}{c}\text { Number of trips } \\
\text { (Nov 2017 - Oct } \\
\mathbf{2 0 1 8}\end{array}$ & $\begin{array}{c}\text { Number of trips } \\
\text { (Nov 2018 - Oct } \\
\mathbf{2 0 1 9})\end{array}$ & $\begin{array}{c}\text { Fuel cost } \\
\text { (per liter) }\end{array}$ & $\begin{array}{c}\text { Transport cost } \\
\text { saving }\end{array}$ \\
\hline A & 131.2 & 4 & 64 & 35 & 101 & $96,071.2$ \\
B & 5.6 & 3 & 35 & 17 & 101 & $3,393.6$ \\
\hline Notes:1 (to consider the effect of reduced number of trips, the fuel price assumed to be constant throughout the period) &
\end{tabular}

Cost saving from reduced waste. Moreover, in both case A and $\mathrm{B}$, the cost of waste management has been reduced due to the use of cotton waste. As explained by respondents, the previous practice of organizations was to send the remaining fabric for external companies by making additional payments. Therefore, the use of cotton waste as a source to produce thermal energy, has also caused considerable reductions in such additional costs. As per the financial records, the reduction of annual costs to a third party is around LKR 162,500 in case A, while it is LKR 23,214.28 in case B.

Unit cost of steam production. Moreover, when analyzing the unit price of steam produced by boilers, respondents in both cases mentioned that the unit price of steam production in biomass boilers has been reduced after the use of cotton waste. $\mathrm{R} 1$ in case A stated that "Earlier unit cost per $1 \mathrm{~kg}$ of steam was LKR 0.56. After shifting to new technique, it became LKR 0.14 per unit." Similarly, R4 in case B mentioned that, they could reduce the unit cost by LKR 4.95 with the use of cotton waste for biomass boilers. Furthermore, according to the cost information of case A, Table 7 indicates the financial savings that can be received through the reduction of unit cost of steam production.

Accordingly, purchasing costs of firewood, unit cost of steam production and additional costs of waste management have been reduced in both cases after the use of cotton waste, demonstrating the financial feasibility of utilizing cotton waste as an energy source for biomass boilers

Table 7. Cost savings by unit cost of steam production

\begin{tabular}{ll}
\hline $\begin{array}{l}\text { Average steam production within one hour by } \\
\text { biomass boiler }(\mathrm{kg} / \mathrm{hr})\end{array}$ & 3000 \\
\hline $\begin{array}{l}\text { Cost of firewood for the operation of biomass boiler } \\
\text { within one hour (when use of firewood is 100\%) }\end{array}$ & $\begin{array}{l}\text { LKR } \\
1680.81\end{array}$ \\
\hline Unit cost of $1 \mathrm{~kg}$ steam production & LKR 0.56 \\
\hline $\begin{array}{l}\text { Cost of firewood for the operation of biomass boiler } \\
\text { within one hour (when use of firewood is 25\%) }\end{array}$ & R20.20 \\
\hline Unit cost of $1 \mathrm{~kg}$ steam production & Rs 0.14 \\
\hline
\end{tabular}




\subsection{Technical feasibility}

Technical feasibility for the use of cotton waste for biomass boilers were investigated considering five major factors including technical knowledge and skills of the staff, efficiency of the boiler, boiler maintenance and calorific value [8].

\subsubsection{Technical knowledge and skills of the staff}

To identify the technical feasibility, availability and level of technical knowledge and skills to the staff were discussed first, during the expert interviews. R1 in case A, asserted that "We have improved the skills relevant to the present practice of using cotton waste for biomass boilers, in technical staff who operates boilers." Awareness programs and training sessions have been conducted by the maintenance department in both case $\mathrm{A}$ and $\mathrm{B}$, especially for boiler operators regarding the use of cotton waste as a fuel for biomass boilers.

\subsubsection{Efficiency of the boilers}

Efficiency of boilers is also significant to identify whether the use of cotton for boilers is technically feasible. However, as revealed by the respondents in both case A and B, efficiency of the biomass boilers has been reduced up to some extent due to the use of cotton waste, as they were unable to implement some energy efficient strategies to the boilers. For example, it is important to retain the flue gas temperature inside the boiler as much as possible, so that can increase the production of steam efficiently. Use of steel coils inside the boilers is one of the methods used to retain the flue gas temperature and thereby increase the temperature for the production of steam. However, due to the use of cotton waste, it has been unable to implement this in the boilers in both cases. R3 in case B mentioned that "Sometimes cotton waste will be cached by the steel coils which cause for an increase of pressure inside the tube, which might lead to dangerous situations. Hence we are not using the steel coils for our biomass boilers.". Similar situation was found in case A and respondents agreed that the efficiency of boilers is reduced due to this situation. Due to this, the boilers have been used without steel coils and to retain the boiler efficiency, air flow of blowers have been considered as a suitable energy saving strategy. In this regard, to retain the flue gas temperature inside the boiler while reducing the amount of unburned cotton, it is important to control the rounds per minute (rpm) of blowers to optimize the required supply air levels, which helps to maximize the combustion and thereby boiler efficiency. Besides, temperature level of flue gas is an indicator of incomplete combustion and feeding of cotton waste and fan speed should be controlled accordingly to ensure the boiler efficiency. R4 highlighted that "Once we experienced high level of temperature in flue gas, we took actions to control feeding of boiler with cotton waste." In this situation, respondents explained that they identified the potential of using more quantities of cotton waste to increase the temperature.

\subsubsection{Maintenance of boilers}

Further, both cases have focused on special arrangements for boiler maintenance activities after using cotton waste to their boilers. Controlling mechanisms of flue gas temperature, to boiler burner chamber was highlighted by respondents as an important consideration for the use of cotton for boilers. In case A, they have used "Gini gadole (fire blocks)" walls to mitigate over heating of fire tubes inside the boilers, from cotton waste burning. Besides, flue gas cyclone dust collector
(CDC) and the wet scrubber mechanisms have been used to manage the emissions of flue gas from boilers. In Case B, they have installed a scrubber to remove the ash and air particles from the flue gas and a water treatment plant for the scrubber cleaning purpose. Moreover, maintenance strategy used for boiler maintenance has been changed from corrective maintenance to preventive maintenance after using cotton waste as an energy source for boilers.

\subsubsection{Calorific value}

As another important consideration, calorific value of energy sources used for boiler operations, was considered in both cases. The purpose of analysing the calorific value was to identify the possibility of using cotton waste as a type of fuel for the boilers by identifying the level of boiler efficiency. Accordingly, calorific value of two samples from case A and two samples form case B were identified. It is required to be conformed with the minimum calorific value regulated by the CEA, to use cotton waste as a fuel for boilers. Since cotton waste is used mixing with biomass, the minimum required calorific value for cotton waste is $3400 \mathrm{kcal} / \mathrm{kg}$ and below levels of calorific value than $3400 \mathrm{kcal} / \mathrm{kg}$ were considered to less boiler efficiency. The calorific values of cotton samples taken from case A and case B, fulfilled the minimum level of requirement, as shown in Table 8 .

Table 8. Calorific values of cotton samples

\begin{tabular}{cc}
\hline Sample of cotton waste & Calorific value (kCal/kg) \\
\hline Sample 01 & 3848 \\
Sample 02 & 3672 \\
Sample 03 & 3900 \\
Sample 04 & 3463 \\
\hline
\end{tabular}

When analyzing the requirements that should be fulfilled to achieve the technical feasibility, based on the technical knowledge and skills of the staff, efficiency of boilers, maintenance of boilers and calorific values, this study has identified that the use of cotton waste for biomass boilers is technically feasible in both cases.

\subsection{Legal feasibility}

Legal feasibility was identified next in this study, considering the legal requirements related to the boiler operations, environmental regulations and apparel waste management related legal requirements. As mentioned by the respondents, the approval from $\mathrm{BOI}$ is essential to practice the technique of using cotton waste for biomass boilers as a secondary energy source, since the BOI is legally bonded with national environmental act and factory ordinances. As mentioned in the BOI regulations, "Only rubber wood and cotton waste generated from the cutting of $100 \%$ cotton fabric shall be used as fuel for the boiler. If any other source of fuel are used other than mentioned in the provisions, prior approval shall be obtained from the BOI/CEA and the other relevant organizations".

Accordingly, proofing reports of cottons, fabric testing reports, emission testing reports, periodical boiler maintenance reports should be submitted to the authorities periodically by both cases, to fulfil the legal requirements. Further, it has also been mentioned that "In the boiler feed, total calorific value of cotton \& wood mix should confirm the recommended calorific value for the combustion chamber and the cotton feed at nighttime shall not be permitted". Besides, according to the regulations of BOI and 
environmental authority, the ash generated from any process should be disposed in a way that those are not mixed with rainwater in any circumstances. BOI has also given the authority to check boiler operations in every 3 -month periods and every periodical investigation, the organizations should prove the information for the standards given by the BOI. As shown in Table 9, the maximum value for the soot and dust is $200 \mathrm{mg} / \mathrm{Nm}^{3}$ and maximum percentage value for the smoke opacity is $20 \%$.

Table 9. Standard values for soot and dust and smoke opacity

\begin{tabular}{cc}
\hline Parameters & Standard \\
\hline Soot and dust & $200 \mathrm{mg} / \mathrm{Nm}^{3}$ \\
\hline Smoke opacity & $20 \%$ \\
\hline
\end{tabular}

In terms of the waste management requirements, respondents in both cases highlighted that, it is required to follow the $3 \mathrm{R}$ waste management policy given by the BOI, and both cases have already fulfilled requirements and practiced waste management policies. Accordingly, the legal feasibility was also confirmed for the use of cotton waste for biomass boilers.

\subsection{Social feasibility}

Social feasibility for the use of cotton waste as an energy source for the boilers, was also analyzed in this study, considering main three perspectives including, impact for the staff, impact for the small- scale manufacturers and impact for the firewood suppliers.

From employees' point of view, use of cotton waste for boilers has been a positive action since it was convenient for the staff in transporting, handling, controlling and managing compared to the biomass. As mentioned by the respondents in case B, the potential for hazards in the operation of boilers using cotton waste has been reduced since the feeding of cotton waste to the boilers is done mechanically instead of manually. Idling time in arranging the cotton stocks has been reduced than previously and thereby time wastage is also reduced. When analyzing the impact for the small manufacturers, use of cotton waste within the factory has been adversely affected for small scale manufactures since both cases have stopped selling usable fabric waste to them. From firewood providers perspective, the same situation can be found, since the quantity of purchasing the firewood is considerably less in both cases. As reported by firewood suppliers, it has been around Rs 349,560 loss for the firewood suppliers of case A, while it is a 112,500 loss for the firewood suppliers of case B. There is a significant impact for these parties due to change of practice of the use of energy source for boilers, and therefore, it can be mentioned that, even though it is feasible from the organizational perspective, social feasibility is not entirely achieved.

\subsection{Environmental feasibility}

As the final parameter, environmental feasibility was analyzed in this study for the use of cotton waste for biomass boilers. To analyze the environmental feasibility, approval from relevant authorities were important to be recognized. As mentioned by the respondents, both cases have granted the permission for the use of cotton waste for their biomass boilers. $\mathrm{R} 2$ and $\mathrm{R} 4$ stated that, "We have received the report from central environment authority stating the approval to practice the technique of using cotton waste for the biomass boilers as fuel." In order to get the approval from CEA, it is significant to fulfil the requirements of the levels of emission of flue gas from boilers, to ensure that the use of cotton waste as a practice does not cause adverse impacts to the environment.

Flue gas emissions were considered as it is the globally recognised regulation to ensure the less impact of boiler emissions to the environment. Garment manufacturing industry should ensure the less emission of adverse flue gas components to the environment from the boilers used. Hence, it is required to measure the flue gas components of boiler emissions after using cotton waste to check whether it increases the emission of adverse flue gas components or not.

The values of flue gas components by the usage of cotton waste with firewood according to the ratios are presented by Table 10 and 11, as identified from the flue gas emission reports in both cases. Table 10 shows the details of Case A while Table 11 shows details of flue gas emissions of case B.

Table 10. Flue gas components

\begin{tabular}{ccc}
\hline Parameter & Unit & $\begin{array}{c}\text { Concentration at each fuel } \\
\text { combination }\end{array}$ \\
\hline & & Use of ratio cotton and firewood \\
$75: 25$ \\
$\mathrm{O}_{2}$ & $\%$ & 16.4 \\
$\mathrm{H}_{2} \mathrm{O}$ & $\%$ & 0.05 \\
$\mathrm{PM}$ & $\mathrm{Mg} / \mathrm{Nm}^{3}$ & 0 \\
$\mathrm{CO}$ & $\%$ & 3.45 \\
$\mathrm{CO}$ & $\mathrm{Mg} / \mathrm{Nm}^{3}$ & 785 \\
$\mathrm{SO}$ & $\mathrm{Mg} / \mathrm{Nm}^{3}$ & 46 \\
$\mathrm{NO}_{\mathrm{x}}$ & $\mathrm{Mg} / \mathrm{Nm}^{3}$ & 86 \\
$\mathrm{Boiler}$ exhaust & 112 \\
temperature & \\
\hline \multicolumn{2}{c}{}
\end{tabular}

Table 11. Flue gas components

\begin{tabular}{cccc}
\hline & Unit & $\begin{array}{c}\text { Concentration at each fuel } \\
\text { combination } \\
\text { Parameter }\end{array}$ & \multicolumn{2}{c}{$\begin{array}{c}\text { Firewood } \\
\text { Fitio; Cotton and }\end{array}$} \\
\hline & & $100: 0$ & $80: 20$ \\
$\mathrm{O}_{2}$ & $\%$ & 13 & 11 \\
$\mathrm{H}_{2} \mathrm{O}$ & $\%$ & 21 & 19 \\
$\mathrm{PM}$ & $\mathrm{Mg} / \mathrm{Nm}^{3}$ & 107 & 142 \\
$\mathrm{CO}$ & $\%$ & 15 & 11 \\
$\mathrm{CO}$ & $\mathrm{Mg} / \mathrm{Nm}^{3}$ & 201 & 146 \\
$\mathrm{SO}$ & 10 & 6 \\
$\mathrm{NO}_{\mathrm{X}}$ & $\mathrm{Mg} / \mathrm{Nm}^{3}$ & 123 & 125 \\
Boiler exhaust & $\mathrm{Mg} / \mathrm{Nm}^{3}$ & & 142 \\
temperature & & 146 & \\
\hline
\end{tabular}

According to the flue gas emission reports, both cases have not exceeded the emission limits of flue gases except the PM and $\mathrm{NO}_{\mathrm{x}}$ in case $\mathrm{B}$, and the percentages of other flue gas components have been reduced after the use of cotton mixing with firewood. The percentage of $\mathrm{O}_{2}$ content has been reduced to $11 \%$ in case $\mathrm{B}$, after using cotton and it was $13 \%$, when using firewood only. The reduction of $\mathrm{O}_{2}$ is evident because the use of $\mathrm{O}_{2}$ has been increased for the combustion and thereby it indicates an efficient combustion. Importantly, emissions of greenhouse gases including $\mathrm{CO}_{2}, \mathrm{CO}$ and $\mathrm{SO}_{2}$ have been reduced after the use of cotton waste with firewood. Particulate matter (PM) content has been increased after the use of cotton waste due to the high collection of ash. 
To reduce the extra generated particulates, both cases have used water scrubbers specially to dilute the ash content and remove the big particles comes from cotton combustion. Further, to reduce the resulting percentage of $\mathrm{NO}_{\mathrm{x}}$ in case $\mathrm{B}$, the maintenance department has decided to use low $\mathrm{NO}_{x}$ burner to the boiler which can reduce the concentration of NOx by $30 \%$. Case A shows the reduced values of flue gas components after the usage of cotton waste which are acceptable to the required limits. Besides, flue gas temperature has been reduced in both cases which is important to satisfy with the environmental feasibility as it ensures the reduction of temperature emitted to the environment. As explained by R2 "We are highly considering the emission of air temperature so that we always try to reduce the temperature of the exhaust air as that we are using the water spray system that will be reducing the emissions air temperature." In case A, a water spray system has been further used to reduce the temperature of flue gas emitted to the environment. Moreover, as identified from both cases, due to the reduction of transportation of firewood for boilers, it has positively affected the carbon footprint as well. Table 12 shows the reduction of $\mathrm{CO}_{2}, \mathrm{CH}_{4}, \mathrm{~N}_{2} \mathrm{O}$ and $\mathrm{CO}_{2}$ by the transportation, after the use of cotton for the boilers in both cases.

Moreover, the environmental feasibility was assessed analyzing the level of damage to the human health, ecosystem and resources. ReCiPe Endpoint $(\mathrm{H}) /$ Europe ReCiPe analysis method was used to get the results of damage level for the aforementioned three criteria, using the data of flue gas emissions and transportation related information. Results of the analysis are represented in graph 01. Basically, six processes were selected to assess the damage levels. These processes are indicated in Table 13.

Accordingly, damage assessment for the human health, eco system and resources due to the use of cotton waste is demonstrated in Figure 2. It shows the levels of damages under each type of process and thereby the optimum ratio of firewood and cotton can be analyzed.

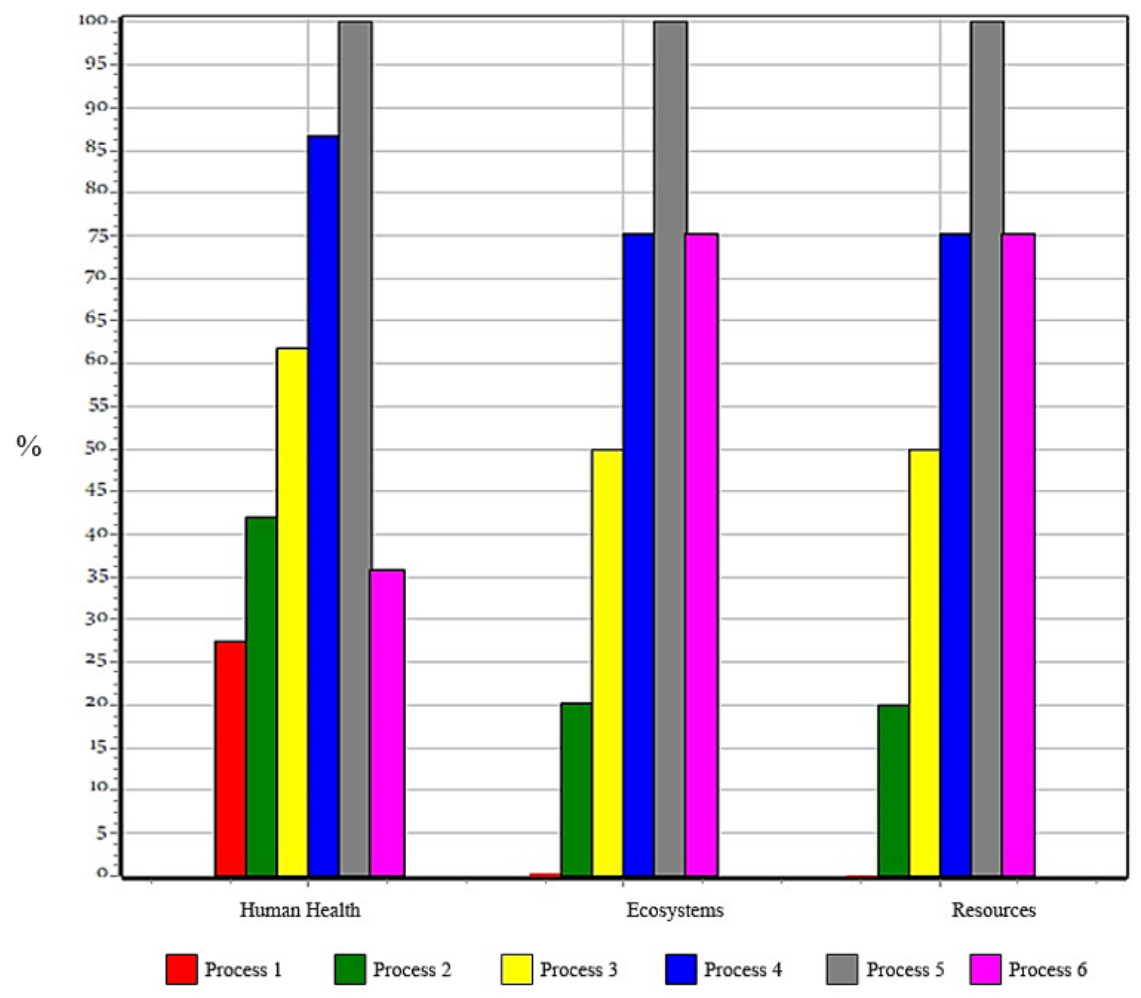

Figure 2. Damage level assessment

Table 12. Reduction of $\mathrm{CO}_{2}, \mathrm{CH}_{4}, \mathrm{~N}_{2} \mathrm{O}$ and $\mathrm{CO}_{2}$ after the use of cotton

\begin{tabular}{cccccc}
\hline Case & $\begin{array}{c}\text { Combustion of diesel liters for single } \\
\text { transport round }\end{array}$ & $\begin{array}{c}\text { Emission of CO } \\
(\mathbf{k g})\end{array}$ & $\begin{array}{c}\text { Emission of } \mathbf{C H}_{\mathbf{4}} \\
(\mathbf{k g})\end{array}$ & $\begin{array}{c}\text { Emission of } \mathbf{N}_{\mathbf{2}} \mathbf{O} \\
(\mathbf{k g})\end{array}$ & $\begin{array}{c}\text { Emission of CO } \\
(\mathbf{k g})\end{array}$ \\
\hline $\mathrm{A}$ & 32.8 & 87.072 & 0.01968 & 0.6874 & 87.779 \\
$\mathrm{~B}$ & 1.86 & 4.937 & 0.00116 & 0.0389 & 2.488 \\
\hline
\end{tabular}

Table 13. Types of processes for the damage level assessment

\begin{tabular}{cc}
\hline Process Type & Ratio (Firewood: Cotton) \\
\hline Process 1 & $100: 0$ \\
Process 2 & $80: 20$ \\
Process 3 & $50: 50$ \\
Process 4 & $25: 75$ \\
Process 5 & $0: 100$ \\
Process 6 & $75: 25$ \\
\hline
\end{tabular}

According to the results shown by the graph, process 1 and 5 were disregarded for the analysis, as this study focused to identify the level of damage to the above three criteria caused by the use of cotton mixed with firewood. As shown by the remaining processes in overall, process 2 (green) and process 3 (yellow) obviously indicate the optimum ratio of cotton and firewood, since the level of damage to the human health, ecosystems and resources is comparatively less than the other processes. Process 2 shows $40 \%$ of damage for the human health while $20 \%$ for ecosystem and resources. Even though 
process 6 shows less damage level of $35 \%$ for human health than process 2, damage level of process 6 is too high for ecosystems and resources (75\%) compared to process 2 . Thus, process 2 is considered as an optimum ratio based on the analysis. Apart from process 2, process 3 shows less damage level next, as shown in the graph indicating $60 \%$ of damage for the human health and $50 \%$ of damage for ecosystems and resources. That means, process 2 ( $80 \%$ of firewood with $20 \%$ of cotton waste) can be recommended as an optimum ratio which is current being used by case B.

Process 6 (75\% of firewood with $25 \%$ cotton) indicates higher damage to the ecosystems and resources by $75 \%$, which is currently being used by case A. Thus, process 6 cannot be recommended to case A to environmentally be feasible, and accordingly, case A can convert their current ratio to process 2 or 3 . Process 4 also indicates higher damage level by $85 \%$ to human health and $75 \%$ to ecosystems and resources and therefore, process 4 is rejected.

Moreover, the impact of each process was analyzed in terms of the climate change to human health, human toxicity, particulate matter formation, climate change to ecosystems, fresh water eutrophication, fresh water ecotoxicity, ozone depletion, photochemical oxidant formation, ionizing radiation, terrestrial acidification, terrestrial ecotoxicity and marine ecotoxicity. The results are shown in Figure 3.

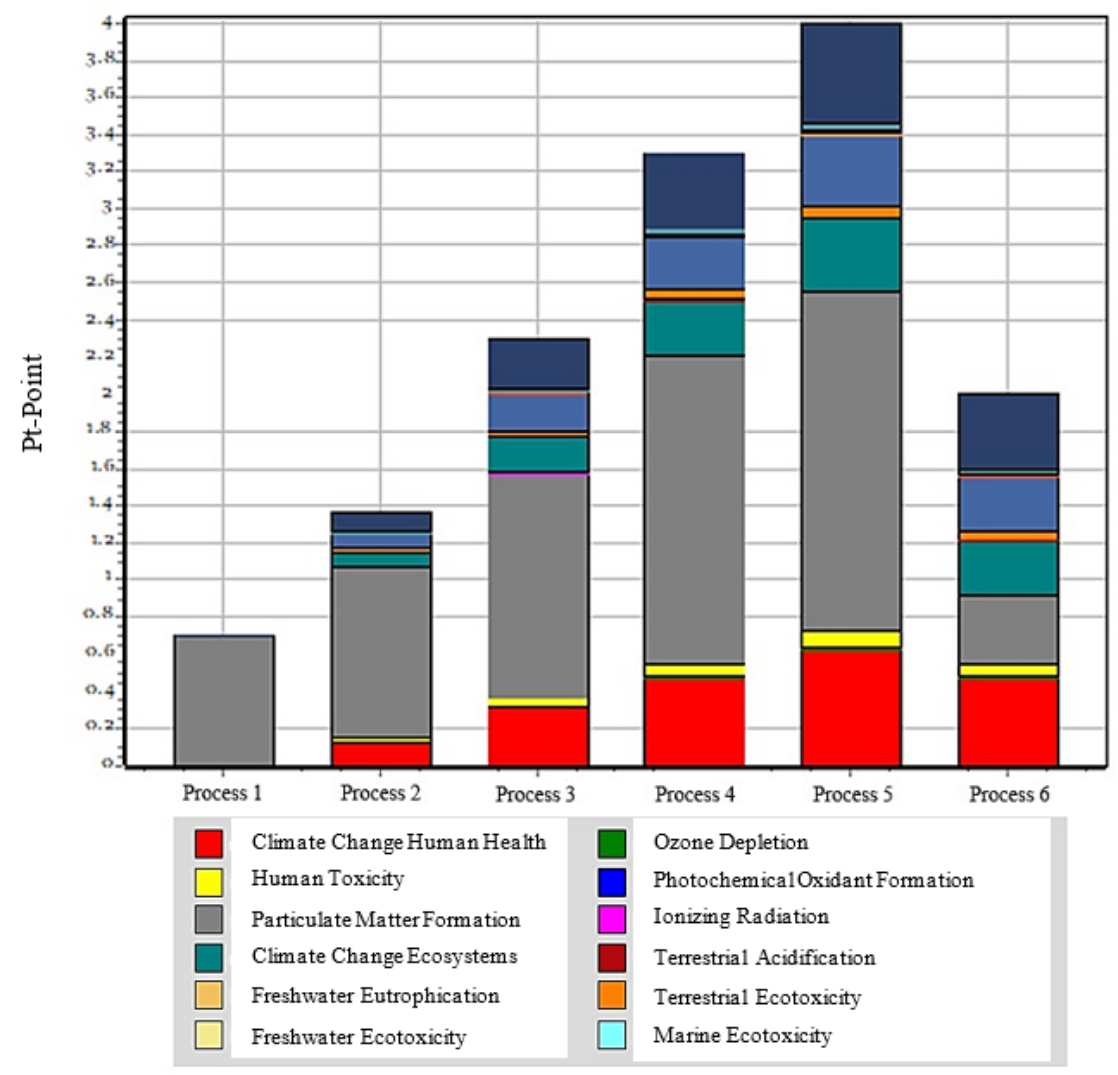

Figure 3. Impact of processes

As shown in the graph, again it is obvious that process 2 and 3 contains less weighted impact to each criterion focused on environmental feasibility. Hence, according to the analysis, process 2 and 3 can be recommended as optimum ratios to be used, to fulfil requirements to environmentally be possible for the use of cotton waste to biomass boilers.

According to the overall results analysed in this study, it is obvious that the use of cotton waste mixing with firewood as a fuel for biomass boilers is entirely feasible in terms of financial feasibility, technical feasibility, legal feasibility and environmentally feasibility. The financial feasibility is achieved since there is a huge saving in overall cost when using cotton waste than firewood only. As the findings of this study under technical feasibility, it was achievable since the required knowledge and skills, maintenance aspects of boilers and required calorific values were acceptable to the standards. However, possibility of using energy saving strategies to the current condition of biomass boilers was less due to the use of cotton waste and thus, future attempts will be necessary to find out the strategies to enhance the efficiency of biomass boilers when cotton is used as an energy source. From legal perspective, use of cotton was entirely feasible as it is fulfilled the requirements governed by the CEA and BOI in Sri Lanka. Besides, the social feasibility was analysed and however, it was not entirely feasible according to this study, since the use of cotton has caused a negative impact up to some extent, to the social parties outside the organizations. Finally, as a major concern, environmental feasibility has also been analysed in this research and in overall, in can be mentioned that the use of cotton as a type of fuel for biomass boilers is environmentally feasible.

\section{DISCUSSION}

With the simultaneous requirements of managing excessive fabric waste and producing thermal energy in apparel manufacturing sector, Nunes et al. [8] have conducted a study to investigate the potential of using fabric waste to produce thermal energy for boilers. The study has mainly focused on 
identifying the characteristics of cotton waste against the other types of fuel used for boilers and financial capability and revenue that can be generated through the use of cotton waste for producing thermal energy. The study has also concluded that use of cotton waste to boilers is an ideal alternative to firewood and therefore, most of prevailing issues associated in using firewood can be eliminated by replacing with cotton waste [32, 33]. However, this study has mainly aimed the economic feasibility and proved the financial savings of using cotton to boilers to produce thermal energy, which was validated in this study as well. Apart from Nunes et al. [8] study, there is no recent studies have been conducted focusing to investigate the feasibility of using cotton waste for biomass. Punchihewa et al. [6] and Al Afif et al. [13], have mentioned in their studies, the potential of using cotton as an energy source and further highlighted the necessity of encouraging future research efforts to identify the feasibility and implement the required strategies for the use of cotton as an energy source for biomass boilers. Specifically, in this study, environmental feasibility, technical feasibility, social feasibility and legal feasibility have been investigated in addition to the economic feasibility considering the Sri Lankan context. Furthermore, this study has proved that the use of cotton waste for biomass boilers is feasible specially from environmental, technical and legal aspects.

\section{CONCLUSIONS, LIMITATIONS AND FUTURE RESEARCH DIRECTIONS}

This study has mainly focused on identifying the feasibility of using cotton waste for biomass boilers in apparel manufacturing sector. Basically, feasibility was assessed through the predetermined criteria including environmental feasibility, technical feasibility, financial feasibility, social feasibility and legal feasibility. Each criterion was separately analysed conducting semi-structured interviews and document surveys in order to identify the feasibility. According to the findings environmental, technical, financial and legal feasibility were justified while social feasibility was not entirely acceptable. However, in overall, this study summarises the feasibility of using cotton waste as an alternative energy source for creating thermal energy for biomass boilers. This is important to the apparel sector to eliminate the issues associated with the management of cotton waste and supply of firewood for biomass boilers. The findings of this study are case-specific. However, each case has been analysed in detail to identify the feasibility. Garment manufacturing industry may comprise different scale of factories as small scale, medium or large scale. Based on each scale and standards used in each particular company, the feasibility criteria would be differed. However, the knowledge provided in this study using two in depth cases, is beneficial for the garment manufacturing industry and can be used as a fundamental knowledge for the use of cotton waste for boilers as an energy source. Thus, the findings are also applicable for both local and international context.

Future studies can be conducted extending this research, focusing the feasibility of using other types of fabric waste as energy sources to produce thermal energy. Moreover, as boiler efficiency is significant to be considered, it is necessary to find out how the combustion efficiency can be achieved in biomass boilers when cotton is used with firewood for biomass boilers. Currently, excess air level calculations are performed to analyse the combustion efficiency of boilers and the generally accepted excess air level is $10 \%$ for firewood used boilers. However, there is no recommended level to be analysed for the combination of cotton and firewood for biomass boilers which was a limitation of this study. The selected cases in this study have basically concerned the environmental feasibility and no prevailing standards have been established to assess the combustion efficiency of boilers for the use of cotton with firewood. Hence, it is important to investigate through future practical experiments, the optimum level of combustion efficiency to be achieved by the proportionate use of cotton and firewood for biomass boilers, to further be compatible with the technical feasibility. This study has proved the feasibility of using cotton waste for biomass boilers in terms of financial, environmental, technical and legal perspectives. However, the presented findings of social and legal criteria are mainly related to the Sri Lankan context and it is important to examine the different impacts and forces that can be exposed in other contexts. Moreover, this study has limited to the apparel manufacturing industry where biomass boilers are used for large scale productions. Nevertheless, other industries including hotels and residential apartments where boilers are mainly used for large scale productions will be opened to future research investigations to identify the unique findings that can be exposed by social and legal perspectives.

\section{REFERENCES}

[1] Shuit, S.H., Tan, K.T., Lee, K.T., Kamaruddin, A.H. (2009). Oil palm biomass as a sustainable energy source: A Malaysian case study. Energy, 34(9): 1225-1235. https://doi.org/10.1016/j.energy.2009.05.008

[2] McManus, M.C. (2010). Life cycle impacts of waste wood biomass heating systems: A case study of three UK based systems. Energy, 35(10): 4064-4070. https://doi.org/10.1016/j.energy.2010.06.014

[3] Münster, M., Meibom, P. (2011). Optimization of use of waste in the future energy system. Energy, 36(3): 16121622. https://doi.org/10.1016/j.energy.2010.12.070

[4] Na, Y., Na, D.K. (2015). Investigating the sustainability of the Korean textile and fashion industry. International Journal of Clothing Science and Technology, 27(1): 2333. https://doi.org/10.1108/IJCST-08-2013-0085

[5] Filho, W., Ellams, D., Han, S., Tyler, D., Boiten, V.J., Paço, A., Moora, H., Balogun, A.L. (2019). A review of the socio-economic advantages of textile recycling. Journal of Cleaner Production, 218: 10-20. https://doi.org/10.1016/j.jclepro.2019.01.210

[6] Punchihewa, S.S., Chandrakumar, C., Kulatunga, A.K. (2016). Adaptation of biomass based thermal energy generation of Sri Lankan manufacturing sector: Paragon for policy development. In: Procedia CIRP, 40: 56-61. https://doi.org/10.1016/j.procir.2016.01.054

[7] Bodur, M.S., Sonmez, H.E., Bakkal, M. (2017). An investigation for the effect of recycled matrix on the properties of textile waste cotton fiber reinforced (T-FRP) composites. Polym. Compos., 38(7): 1231-1240. https://doi.org/10.1002/pc.23687

[8] Nunes, L.J.R., Godina, R., Matias, J.C.O., Catalão, J.P.S. (2018). Economic and environmental benefits of using textile waste for the production of thermal energy. $\mathrm{J}$ Clean Prod., 171: 1353-1360. https://doi.org/10.1016/j.jclepro.2017.10.154 
[9] Gholamzad, E., Karimi, K., Masoomi, M. (2014). Effective conversion of waste polyester-cotton textile to ethanol and recovery of polyester by alkaline pretreatment. Chem. Eng. J., 253: 40-45. https://doi.org/10.1016/j.cej.2014.04.109

[10] Choi, T.M., Lo, C.K.Y., Wong, C.W.Y., Yee, R.W.Y. (2012). Green manufacturing and distribution in the fashion and apparel industries. Int. J. Prod. Econ., 135(2): 531. https://doi.org/10.1016/j.ijpe.2011.07.012

[11] Muthukumarana, T.T., Karunathilake, H.P., Punchihewa, H.K.G., Manthilake, M.M.I.D., Hewage, K.N. (2018). Life cycle environmental impacts of the apparel industry in Sri Lanka: Analysis of the energy sources. Journal of Cleaner Production, 172: 1346-1357. https://doi.org/10.1016/j.jclepro.2017.10.261

[12] Ryu, C., Phan, A.N., Sharifi, V.N., Swithenbank, J. (2007). Co-combustion of textile residues with cardboard and waste wood in a packed bed. Experimental Thermal and Fluid Science, 32(2): 450-458. https://doi.org/10.1016/j.expthermflusci.2007.05.008

[13] Al Afif, R., Pfeifer, C., Pröll, T. (2019). Bioenergy Recovery from Cotton Stalk. In: Cotton Research. Intechopen. https://doi.org/10.5772/intechopen.88005

[14] Board of Investments (BOI) Investment Opportunities; Apparel.

[15] Munasinghe, M., Jayasinghe, P., Ralapanawe, V., Gajanayake, A. (2016). Supply/value chain analysis of carbon and energy footprint of garment manufacturing in Sri Lanka. Sustain Prod Consum., 5: 51-64. https://doi.org/10.1016/j.spc.2015.12.001

[16] Laitala, K., Klepp, I.G. (2015). Clothing disposal habits and consequences for life cycle assessment (LCA). Handbook of Life Cycle Assessment (LCA) of Textiles and Clothing, 345-365. https://doi.org/10.1016/B978-008-100169-1.00016-2

[17] Gunathilaka, D., Gunewardena, K. (2014). Analysis of Carbon-off setting targets towards sustainable economic development in apparel sector organization in Sri-Lanka. International Journal of Trade, Economics and Finance, 5: 360-363. https://doi.org/10.7763/IJTEF.2014.V5.398

[18] Leckner, B. (2015). Process aspects in combustion and gasification Waste-to-Energy (WtE) units. Waste Manag., $\quad 37$ 13-25 https://doi.org/10.1016/j.wasman.2014.04.019

[19] Kakareka, S.V., Kukharchyk, T.I., Khomich, V.S. (2005). Study of PAH emission from the solid fuels combustion in residential furnaces. Environ Pollut, 133(2): 383-387. https://doi.org/10.1016/j.envpol.2004.01.009

[20] Halimi, T.M., Hassen, B.M., Azzouz, B., Sakli, F. (2007). Effect of cotton waste and spinning parameters on rotor yarn quality. The Journal of The Textile Institute, 98(5): 437-442. https://doi.org/10.1080/00405000701547649

[21] Nunes, L.J.R., Matias, J.C.O., Catalao, J.P.S. (2013). Economic evaluation and experimental setup of biomass energy as sustainable alternative for textile industry. In: Proceedings of the Universities Power Engineering Conference, Dublin, Ireland, pp. 1-6.
https://doi.org/10.1109/UPEC.2013.6714907

[22] Department of Environmental Affairs and Tourism in South Africa (2011). Highveld priority area air quality management plan.

[23] Cherubini, F., Bird, N.D., Cowie, A., Jungmeier, G., Schlamadinger, B., Woess-Gallasch, S. (2009). Energyand greenhouse gas-based LCA of biofuel and bioenergy systems: Key issues, ranges and recommendations. Resources, Conservation and Recycling, 53(8): 434-447. https://doi.org/10.1016/j.resconrec.2009.03.013

[24] Pierobon, F., Zanetti, M., Grigolato, S., Sgarbossa, A, Anfodillo, T., Cavalli, R. (2015). Life cycle environmental impact of firewood production - A case study in Italy. Appl Energy, 150: 185-195. https://doi.org/10.1016/j.apenergy.2015.04.033

[25] Patel, B., Gami, B., Bhimani, H. (2011). Improved fuel characteristics of cotton stalk, prosopis and sugarcane bagasse through torrefaction. Energy for Sustainable Development, 15(4): 372-375. https://doi.org/10.1016/j.esd.2011.05.002

[26] Ali, H. (2010). Energy-Efficiency Improvement Opportunities for the Textile Industry.

[27] Saidur, R., Atabani, A.E., Mekhilef, S. (2011). A review on electrical and thermal energy for industries. Renew Sustain Energy Rev., 15(4): 2073-2086. https://doi.org/10.1016/j.rser.2011.01.008

[28] Hamawand, I., Sandell, G., Pittaway, P., Chakrabarty, S., Yusaf, T., Chen, G.N., Seneweera, S., Al-Lwayzy, S., Bennett, J., Hopf, J. (2016). Bioenergy from Cotton Industry Wastes: A review and potential. Renew Sustain Energy Rev., 66: 435-448. https://doi.org/10.1016/j.rser.2016.08.033

[29] Avelar, N.V., Rezende, A.A.P., Carneiro, A.D.C.O., Silva, C.M. (2016). Evaluation of briquettes made from textile industry solid waste. Renew Energy, 91: 417-424. https://doi.org/10.1016/j.renene.2016.01.075

[30] Allegrini, E., Boldrin, A., Jansson, S., Lundtorp, K., Fruergaard Astrup, T. (2014). Quality and generation rate of solid residues in the boiler of a waste-to-energy plant. J Hazard Mater, 270: 127-136. https://doi.org/10.1016/j.jhazmat.2014.01.048

[31] Olowa, O.A., Olowa, O.W. (2015). Gender issues of labour participation in vegetable production in Ikorodu local government area of lagos state. Curr Res Agric Sci., 2(4): 90-98. https://doi.org/10.18488/journal.68/2015.2.4/68.4.114.1 22

[32] Ismail, Z.Z., Talib, A.R. (2016). Recycled medical cotton industry waste as a source of biogas recovery. J Clean Prod., 112(5): 4413-4418. https://doi.org/10.1016/j.jclepro.2015.06.069

[33] Haule, L.V., Carr, C.M., Rigout, M. (2016). Preparation and physical properties of regenerated cellulose fibres from cotton waste garments. Journal of Cleaner Production, 112(5): 4445-4451. https://doi.org/10.1016/j.jclepro.2015.08.086 